\title{
Challenges and Prospects of Anti-Rabies Vaccines Production in Nigeria
}

\author{
Ishaya Sini Tekki1*, Chika Nwosu and Philip Ademola Okewole
}

National Veterinary Research Institute, Vom Vom, Plateau State, Nigeria

\begin{abstract}
Rabies is one of the oldest known viral zoonosis and remains a serious public health hazard, especially in the developing countries. It is the major viral disease in humans living in the tropics, but it is enzootic worldwide. Though its hundred percent preventable, it is estimated to cause 55,000 deaths annually, at a minimum, because appropriate therapy and preventive measures are not available in most developing countries. Exposure to rabid dogs is responsible for about $90 \%$ of reported cases of human rabies in the world each year. Effective control, prevention and eradication of rabies in man and animal can only be realized by immunization. Despite concerted efforts to develop and produce anti-rabies vaccines for protection of man and animal against rabies since 1919 in Nigeria, successful achievement of effective control and prevention of the disease through vaccination is greatly hampered by poor or lack of modern technology and facilities required for development and production of safe and effective vaccines. High cost of development and production, poor electric power supply, poor policy implementation by governments, poverty and gross lack of awareness are other major constraints encountered in rabies vaccinology in developing counties including Nigeria. Recent advances in tissue culture technologies, genetic engineering and peptide chemistry have made it possible to design and produce large quantities of pure antigens. This is a far reaching prospects for the development and production of life-saving vaccines for humans and animals. This approach aims at development and production of safe, effective, potent, and inexpensive anti-rabies vaccines with longer shelf life, greater quantity in terms of volume of vaccines produced and short immunization schedule than the trial and error approach by which vaccines were developed, produced and used in the past.
\end{abstract}

Keywords: Rabies; Anti-rabies vaccine; Production; Challenges; Prospects; Nigeria

\section{Introduction}

Rabies is a rapidly progressive and uniformly fatal viral meningoencephalitis in humans caused by the rabies or related group of Rhabdoviridae, in the genus Lyssavirus [1]. All mammals are susceptible to rabies, although canine rabies presents the greatest threat to humans, especially in Latin America, Asia and Africa. Despite the fact that rabies is under-reported worldwide, it is estimated to cause 55,000 deaths annually, at a minimum [2]. Exposure to rabid dogs is responsible for about $95 \%$ of reported cases of human rabies in the world each. It is the major viral disease in humans living in the tropics, but it is enzootic worldwide.

Over the years, several types of anti-rabies vaccines have been developed, produced and used for protection of man and animal against rabies. Pasteur's basic approach to vaccine development such as attenuation and inactivation are still key pillars of vaccinology. In modern technology however, purification of target microbial components, genetic engineering and enhanced knowledge of immune defence to enable creation of attenuated mutants, expression of vaccine proteins and polysaccharide [3] have evolved over the years. Five groups of fixed strains of rabies virus are used globally today to produce the diverse kind of rabies vaccines, particularly in cell culture, for human use [3]. The Pasteur-derived strains of rabies virus are the most predominantly used for the production of traditional vaccines of the Semple or Suckling Mouse Brain (SMB) types, but also for the production of modern cell culture vaccines such as Human Diploid and Purified Vero Cell vaccines (HDCV and PVRV) [4]. Generally, vaccines are categorized into: Attenuated or modified live virus (MLV) vaccine; Killed or inactivated virus vaccine; Vaccine grown in brain tissue of adult sheep, rabbit or brain of new born mice, rats or rabbits; Embryonated chicken or duck egg-based vaccine and modern tissue culture based vaccine (MTCV) [5]. Hunt [6] also described four basic types of vaccine in use today.
In Nigeria, the MLV Low Egg Passage (LEP) and High Egg Passage (HEP) flurry strain vaccines were first produced in chick embryo in 1956 and in 1970 for dogs and for cats respectively [7,8]. These are produced only by the National Veterinary Research Institute (NVRI) Vom in Plateau State, Nigeria, which is the national laboratory saddled with the mandate to develop and produce animal vaccines in the country. Despite these early interventions however, previous research finding have shown that dogs succumbed to clinical rabies after previous vaccinations $[9,10]$.

\section{Challenges}

The greatest challenge in the industry of anti-rabies vaccine production for both humans and animals, especially in some developing countries, is little or non-availability of modern technologies in order to transit from production of nerve tissue vaccine (NTV) to the tissue culture (MTCV) [11] or sub-unit vaccines. For instance, due to presence of high content of myelin of the adult brain tissue in Semple vaccine (NTV) there is a high incidence of neuroparalysis after usage of the NTV $[11,12]$. NTV is not only paralyticogenic, it is less convenient, less immunogenic, more reactogenic, less tolerable and less acceptable. In addition, more number of doses is needed and the administration of which comprise comparatively a painful procedure. MTCV however is more antigenic, acceptable, well tolerated, and convenient with less

${ }^{*}$ Corresponding author: Ishaya Sini Tekki, DVM, MSc, National Veterinary Research Institute, Vom Vom, Plateau State, Nigeria, E-mail: sini.tekki@nvri.gov.ng

Received October 21, 2013; Accepted November 28, 2013; Published November 30, 2013

Citation: Tekki IS, Nwosu C, Okewole PA (2013) Challenges and Prospects of Anti-Rabies Vaccines Production in Nigeria. J Vaccines Vaccin 4: 212. doi: 10.4172/2157-7560.1000212

Copyright: $\odot 2013$ Tekki IS, et al. This is an open-access article distributed under the terms of the Creative Commons Attribution License, which permits unrestricted use, distribution, and reproduction in any medium, provided the original author and source are credited. 
reactogenicity [11]. Another constraint is that encephalitis in puppies aged below 3 weeks of age [13] and lack of immunologic response in puppies below 11 weeks of age were listed as the draw backs of the MLV vaccines. It was also said to have short shelf life [14]; and responsible for vaccine-induced rabies in dogs [8], which led to the withdrawal of such vaccines in most developed countries [15].

In Nigeria, another important constraint of rabies vaccine production is high cost of materials, reagents, biological, chemicals, consumables and other supplies. The cost of procurement and maintenance/servicing of equipment such as safety cabinets, dispensing/capping machines, freeze-drying machines, labeling machines, incubators and freezers, to mention a few, can be alarming. The costs of tissue culture used in the production of the tissue culture based vaccines can also be enormous. Acytylethyleneimine and betapropiolactone used for its inactivation are usually very high. In Nigeria, where embryonated chicken or duck eggs are utilized for the attenuation and production of both vaccine seed virus and finished vaccine, the eggs are relatively expensive, though affordable. As there are no facilities available to raise and maintain specific pathogen free breeder stock of poultry for this purpose, it then becomes mandatory to stock and maintain at least a flock of minimally-disease-free birds or procure the embryonated eggs from reputable sources.

As in most developing countries, there are serious challenges with provision of constant electric power, which is an inevitable requirement in any facility where vaccines are produced, stored, handled and transported on industrial scale in Nigeria. Where central nationwide (National grid) supply of electricity is not possible as is the case in many parts of Nigeria today, local generation of power becomes inevitable for production, storage and transportation of vaccine at adequate conditions. The cost of such local generation of power can most times be outrageous. This eventually translates to increase in cost of production and finally increase in the cost of the product.

One other basic difficulty is that the economic demand for vaccines bears no relation to the social pay-off [16]. From a commercial standpoint, the total vaccine market here, in Nigeria and abroad is small. The world's poor, whose children have the greatest need for vaccines, cannot afford to purchase them at market prices.

Cost of vaccines is another problem, as new vaccines require not less than $\$ 300$ - $\$ 800$ million to develop, and the companies doing the research and development must first recover this cost [3]. To alleviate this problem therefore, support from governments and donor agencies to purchase the vaccines for developing countries is necessary [17]. In addition, establishment of vaccine production facilities in developing countries or subsidizing the cost thereof for major manufacturers of vaccines situated in developed or developing countries is necessary, to ensure both availability and affordability of the product to targets. Generally, there is a growing demand for vaccine safety worldwide. One of the advantages of the newer molecular technology is improved safety, although zero risk is not possible [3].

In Nigerian situation, a study carried out by Adeyemi et al. [18], revealed an over $66.0 \%$ increase in the cost of anti-rabies vaccination in dogs between 1995 and 2002 in university of Ibadan, Nigeria, where over a period of ten years, vaccination coverage was only $10.5 \%$ as against $70 \%$ recommended by WHO [19]. From the same study, it was observed that the vaccination coverage was much lower than it was the previous 5 years. This, as in many other cases is an index of low patronage and usage of the available anti-rabies vaccines in the country, including imported foreign and the LEP and HEP produced locally in the country. The sole cause of low patronage and hence low vaccination coverage is basically lack of awareness, poverty and sometimes lack of political will by government authorities.

Another major challenge to be contended with in anti-rabies vaccine development and production in developing countries like Nigeria is absence of enforcement of registration and compulsory vaccination of dogs, free or subsidized vaccine/vaccination cost, regular mass vaccination campaigns and creation of awareness on rabies among the populace $[20,21]$. These result to low patronage of vaccines, and adversely affect production turnover and impetus to embark on developmental research activities. Rabies Immunoglobulin (RIG) is commonly avoided by medical practitioners in Asian countries, leading to treatment failure in the fear of reactogenicity [11]. In some cases, especially in Nigeria, RIG is not available for procurement and use in post exposure management of rabies. These, unknown to the target population, will be presumed to be as a result of outright vaccine failure, leading to loss of confidence in the vaccines, medical personnel and facilities; and subsequently loss of patronage, which will directly be detrimental to any vaccine production industry. Vaccines produced on outdated technologies, such as adult animal brain cultures were used contain myelin, which can provoke a demyelinating immunological disease [21] in the recipients. Compared with modern rabies, cellculture vaccines, the nerve tissue-based vaccines are more reactogenic and may cause severe, even fatal, encephalitis and polyneuritis. Furthermore, NTVs are less potent and require a higher number of painful doses.

\section{Prospects for Vaccine Development}

Recent advances in genetic engineering and peptide chemistry have made it possible to design and produce large quantities of pure antigens - the basic building blocks of vaccines [16]. This implies that, the advent of molecular biology and genetic engineering has played dramatic role on vaccine development [3]. This provides higher opportunities for construction of inactivated antigen and for rational attenuation of organisms through direct mutation. The first successful genetic engineering was with hepatitis $B$ vaccine manufactured in a yeast recombinant carrying the gene for the $S$ protein which replaced a vaccine based on purification of $S$ particles from plasma of infected individual (Diamond, 2011). If scientists can find the antigen of the infecting organism that stimulates immunity, it will probably be possible to produce an effective vaccine (Freeman and Robbins, 1991). It has also been reported that physician-scientists are creating new DNA vaccines that hold great promise for fighting disease more effectively, with fewer side effects [22]. However, the new vaccines are expensive, and funding for the project can be hard to find $[3,22]$. These design approaches are replacing the trial and error by which vaccines were developed in the past [16].

New anti-rabies vaccine development is aimed at producing safe, effective, and inexpensive vaccines that can be given with a short immunization schedule. Several prospective vaccines are in various stages of development. A purified chick embryo cell vaccine [23] has been shown to induce antibodies in monkeys and to protect guinea pigs from disease after parenteral rabies virus challenge. The vaccine is inactivated using beta-propriolactone, and is purified and concentrated by continuous zonal centrifugation. This is becoming a standard technique for removing allergenic materials from vaccine preparations. Highly purified and concentrated forms of the standard duck embryo 
vaccine (DEV) also were being developed [24]. These appear to be more immunogenic and less allergenic than their predecessors, allowing a reduced vaccination schedule. DEV has the advantage of being relatively inexpensive.

Tissue culture techniques have long been used in studies related to rabies virus, and there are now a number of continuous cell line (BHK21, MNA VERO and CER) used in research on pathogenesis, vaccine production and diagnosis of rabies [25,26]. Cell culture rabies vaccines are cleaner, devoid of egg lipids and proteins. It is more potent with longer shelf life and will give greater quantity in terms of volume of vaccines produced. An alternative cell culture medium is a continuous, aneuploid cell line derived from the vervet monkey kidney, called Vero [21]. This process allows higher yields of vaccine antigens than the HDCV approach and may be cheaper and more appropriate for use in the developing world (Ghosh, 2005). The last mentioned category of rabies vaccines are currently produced and used in most developed countries, while the live attenuated dog and cat anti-rabies vaccines are still in use in Nigeria. However, [24] reported a finding that strongly suggests that attenuation of Flury virus results from the harmonic co-evolution of $\mathrm{G}$ and $\mathrm{L}$ elements could be important information for the generation of safer and more effective modified live rabies vaccines. For example, the Ethiopian Health and Nutrition Research Institute manufactured a safe Vero cell culture based rabies vaccine "ETHIORAB" [27] which is safe and showed rabies neutralizing antibody titre higher than the $0.5 \mathrm{IU} / \mathrm{ml}$ mandated WHO threshold [28]. This is an indication that there is very good hope for Nigeria and other developing countries to improve on the present position with regards to modern rabies vaccine production technologies for effective control of rabies.

Correction of discrepancy of the G protein produced using recombinant DNA technology [29] by site-directed mutagenesis appears to be possible [30-32], which suggests that it may be possible to develop a totally synthetic rabies vaccine using this technique. Such a vaccine would contain neither whole virus particles nor the reactogenic components of cell culture vaccines. Thus, inactivation procedures would be unnecessary, and less complex purification techniques might be possible. A recombinant vaccinia virus expressing the rabies $\mathrm{G}$ protein has also been developed [33]. Inoculation of mice with the altered vaccinia vector virus induced immunity that was protective even against severe intracerebral challenge with live rabies virus [31]. This is another promising vaccine candidate.

Nel et al. [34] documented the construction of four DNA vaccines from the glycoprotein $(\mathrm{G})$ and nucleoprotein $(\mathrm{N})$ genes from a South African Mokola virus for immunization against Mokola virus. Two of the single G-expressing DNA vaccines (based on pSG5 and pCI-neo, respectively) protected laboratory mice against lethal challenge; Serological detection of virus-neutralizing antibodies post immunization, which titre increased upon administration of booster dose, gives a good prospect for advances in production of anti-rabies as well as anti-rabies related viruses vaccines for both animal and human use. DNA vaccines have been tested for their efficiency in several animal species and it has been found to offer protection comparable with those obtained with the inactivated vaccines [35-37]. The results of the study conducted in mice, showed that a single administration of the rabies DNA vaccine may be as effective as at least five injections of the cellculture-derived vaccine [38]. Vector vaccines were found capable of inducing an immune response in dogs $[39,40]$. A recombinant rabies virus vaccine carrying two identical glycoprotein $(\mathrm{G})$ genes (SPBNGAGA) has also been constructed [41].

\section{Conclusion}

Vaccines developed over the first 2 centuries since the lifetime of Edward Jenner has greatly achieved reductions of infections and disease wherever utilized. Leius Pasteur's early approach to vaccine development was attenuation and inactivation. But today, purification of microbial elements, genetic engineering and improved technical knowhow of immune protection gives room for attenuation of mutants, expression of vaccine proteins in live vector, purification and synthesis of microbial antigens and induction of a variety of immune response through DNA, RNA and proteins manipulations. Both infectious and noninfectious diseases are now within the realm of vaccinology [3,42-47]. These new developments however come with their attendant problems, in the production, regulation and distribution of vaccines. In the middle of the $20^{\text {th }}$ century, cell culture was adapted to virus growth, attenuation and eventual development of numerous attenuated virus vaccines [3,48-50].

The idea of complete inactivation of microorganisms as a means of vaccine development started in the $20^{\text {th }}$ century. Although it is clear that prospects for control of disease by vaccination are bright, but it is not without its attendant problems such as limited supply of vaccine - this occurs mainly in the developed countries because there are a few manufacturers, and regulatory pressures makes production more difficult. Consequently, the growth of new manufacturers in the developing countries of India, china, Brazil Indonesia, etc., will go a long way to reduce this gap $[3,51,52]$. Developing countries, including Nigeria therefore, have prospect improving animal anti-rabies vaccine through transfer of existing modern technologies of vaccine development and production for the effective control of rabies in the country.

\section{References}

1. Christopher A, Pereira HG (1972) Viruses of the Vertebrates 190-196

2. WHO (2012) WHO Expert Consultation on Rabies. WHO Technical Report Series 982.

3. Plotkin SA (2005) Vaccines: Past, Present and Future: Historical Perspective Natute Medicine Supplement 11.

4. Roumiantzeff M (1988) The present status of rabies vaccine development and clinical experience with rabies vaccine. Southeast Asian J Trop Med Public Health 19: 549-561.

5. Sherman M (1999) Rabies: A History and Update on Prophylaxis Regimens in the U.S.

6. Hunt R (2009) Vaccines: Past Successes And Future Prospects. University of South Carolina School of Medicine.

7. Lamorde AG (1981) Rabies in Nigeria: Prevalence and Control. A Paper Presented at National Anti-rabies Campaign Implementation Workshop.

8. Ogboegbulem SA (1994) Rabies in Man and Animals. Fidelity Publishers, 12 Unije Street Independence Layout Enugu 22-60.

9. Okoh AE (1982) Canine rabies in Nigeria, 1970 - 1980 reported cases in vaccinated dogs. Int J Zoonoses 9: 118-125.

10. Okoh AE (2000) Antigenic characterization of rabies virus isolates from vaccinated dogs in plateau state, Nigeria. Vet Res Commun 24: 203-211.

11. Ghosh TK (2005) Bihar Pedicon -Conference Abstracts. Pediatric On call.

12. Acha PN (1981) A Review of Rabies Prevention and Control in the Americas, 1970-1980: Overall status of rabies. Bull Off Int Epiz 93: 9-52.

13. Steele JH (1973) The epidemiology and control of rabies. Scand J Infect Dis 5: 299-312.

14. Dean DJ, Evans WM, Thompson WR (1964) Studies on the Low Egg Passage Flury Strain of Modified Live Rabies Virus Produced in Embryonating Chicken Eggs and Tissue Culture. Am J Vet Res 25: 756-763. 
Citation: Tekki IS, Nwosu C, Okewole PA (2013) Challenges and Prospects of Anti-Rabies Vaccines Production in Nigeria. J Vaccines Vaccin 4: 212. doi: 10.4172/2157-7560.1000212

15. Ogunkoya AB (1977) Rabies: Basic Concepts, Problems and Prospects of its Control in Nigeria. Oreofe Nig. Limited Publishers, Akure, Nigeria, 78-97.

16. Freeman $P$, Robbins A (1991) The Elusive Promise of Vaccines. The American Prospect Webzine

17. WHO (2010) Animal rabies control.

18. Adeyemi IG, Adetunji VO, James VO, Alonge DO (2005) Ten-Year (1993 2002) Retrospective Evaluation of Vaccination of Dog against Rabies at the University of Ibadan, Nigeria. African Journal of Biomedical Research 8: 71-77.

19. WHO (1989) Guidelines for dog rabies control. WHO VPH/83.43 Rev 1, 5.15.

20. Fagbami AH, Anosa VO, Ezebuiro EO (1981) Hospital records of human rabies and antirabies prophylaxis in Nigeria 1969-78. Trans R Soc Trop Med Hyg 75: 872-876.

21. WHO (1984) Expert Committee on Rabies. Seventh report. World Health Organization, Geneva.

22. Diamond JS (2011) Vaccines in the Vanguard. Penn Medicine 50: 365-369.

23. Barth R, Gruschkau H, Jaeger O, Milcke L, Weinmann E (1984) Purified chick embryo cell (PCEC) rabies vaccine for human use. Laboratory data. Behring Inst Mitt : 142-154.

24. Barth R, Gruschkau H, Jaeger O (1985) Chick-embryo-Cell Inactivated Rabies Vaccine for Veterinary Use. Laboratory and Field Experience. Springer Verlag, Berlin, Germany.

25. Wiktor TJ, Clark HF (1975) Growth of Rabies Virus in Cell Culture. Academic Press, Inc., New York 155-179.

26. King AA (1996) Cell Culture of Rabies Virus. WHO, Geneva, Switzerland 114130

27. Birhanu Hurisa, Belete Tegbaru, Dagmar Nolkes, Abebe Mengesha, Gezahegn Kebede, et al. (2013) Safety and Immunogenicity of ETHIORAB Rabies Vaccine. J Vaccines Vaccin 4: 1.

28. Birhanu Hurisa, Abebe Mengesha, Bethlehem Newayesilassie, Sisay Kerga, Gezahegn Kebede, et al. (2013) Production of Cell Culture Based Anti- rabies Vaccine in Ethiopia. Procedia in Vaccinology 7: 2-7.

29. Wunner WH, Dietzschold B, Curtis PJ, Wiktor TJ (1983) Rabies subunit vaccines. J Gen Virol 64: 1649-1656.

30. Koprowski H, Wiktor TJ, Abelseth MK (1985) Crossreactivity and Crossprotection: Rabies Variants and Rabies-Related Viruses. Springer-Verlag, Berlin 30-39.

31. Lathe R (1985) Synthetic Oligonucleotide Probes Deduced from Amino Acid Sequence Data: Theoretical and Practical Considerations. J Mol Biol 183: 1-12.

32. Faber M, Faber ML, Papaneri A, Bette M, Weihe E, et al. (2005) A single amino acid change in rabies virus glycoprotein increases virus spread and enhances virus pathogenicity. J Virol 79: 14141-14148.

33. Wiktor TJ, Macfarlan RI, Reagan KJ, Dietzschold B, Curtis PJ, et al. (1984) Protection from rabies by a vaccinia virus recombinant containing the rabies virus glycoprotein gene. Proc Natl Acad Sci U S A 81: 7194-7198.

34. Nel LH, Niezgoda M, Hanlon CA, Morril PA, Yager PA, et al. (2003) A comparison of DNA vaccines for the rabies-related virus, Mokola. Vaccine 21 2598-2606.

35. Wang Y, Xiang Z, Pasquini S, Ertl HC (1998) Effect of passive immunization or maternally transferred immunity on the antibody response to a genetic vaccine to rabies virus. J Virol 72: 1790-1796.

36. Perrin $P$, Jacob $Y$, Aguilar-Sétien A, Loza-Rubio E, Jallet C, et al. (1999) Immunization of dogs with a DNA vaccine induces protection against rabies virus. Vaccine 18: 479-486
37. Lodmell DL, Parnell MJ, Bailey JR, Ewalt LC, Hanlon CA (2002) Rabies DNA vaccination of non-human primates: post-exposure studies using gene gun methodology that accelerates induction of neutralizing antibody and enhances neutralizing antibody titers. Vaccine 20: 2221-2228.

38. Bahloul C, Ahme SB, B'chir BI, Kharmachi H, Hayouni A, et al. (2003) PostExposure Therapy in Mice against Experimental Rabies: A Single Injection of DNA Vaccine is as Effective as Five Injections of Cell Culture-Derived Vaccine. Vaccine 22: 177-184

39. Xuan X, Tuchiya K, Sato I, Nishikawa Y, Onoderaz Y, et al. (1998) Biological and immunogenic properties of rabies virus glycoprotein expressed by canine herpesvirus vector. Vaccine 16: 969-976.

40. Hu L, Ngichabe C, Trimarchi CV, Esposito JJ, Scott FW (1997) Raccoon poxvirus live recombinant feline panleukopenia virus VP2 and rabies virus glycoprotein bivalent vaccine. Vaccine 15: 1466-1472.

41. Faber M, Pulmanausahakul R, Hodawadekar SS, Spitsin S, McGettigan $\mathrm{JP}$, et al. (2002) Overexpression of the rabies virus glycoprotein results in enhancement of apoptosis and antiviral immune response. J Virol 76: 3374 3381.

42. Arya SC (1994) Human Immunization in Developing Countries: Practical and Theoretical Problems and Prospects. Vaccine 12: 1423-1435.

43. Brochier B, Kieny MP, Costy F, Coppens P, Bauduin B, et al. (1991) Largescale eradication of rabies using recombinant vaccinia-rabies vaccine. Nature 354: $520-522$

44. Koprowski H (2002) [Old and new prescriptions for infectious diseases and the newest recipes for biomedical products in plants]. Arch Immunol Ther Exp (Warsz) 50: 365-369.

45. Tao L, Ge J, Wang X, Zhai H, Hua T, et al. (2010) Molecular basis of neurovirulence of flury rabies virus vaccine strains: importance of the polymerase and the glycoprotein R333Q mutation. J Virol 84: 8926-8936.

46. Meslin FX, Fishbein DB, Matter HC (1994) Rationale and prospects for rabies elimination in developing countries. Curr Top Microbiol Immunol 187: 1-26.

47. OIE (2013) Manual of Diagnostic Tests and Vaccines for Terrestrial Animals 2013.

48. Tierkel ES, Kissling RE, Eidson M, Habel K (1953) A Brief Survey and Progress Report of Controlled Comparative Experiments in Canine Rabies Immunization. Proc.89th Annual Meeting. AVMA, Toronto, Canada 443-445.

49. Webster LT (1939) A mouse test for measuring the immunizing potency of antirabies vaccines. J Exp Med 70: 87-106.

50. Wiktor TJ, Sokol F, Kuwert E, Koprowski H (1969) Immunogenicity of concentrated and purified rabies vaccine of tissue culture origin. Proc Soc Exp Biol Med 131: 799-805

51. WHO (2008) WHO Expert report on rabies. Rabies- a neglected zoonotic disease. Geneva, Switzerland.

52. Winkler WG, Bögel K (1992) Control of rabies in wildlife. Sci Am 266: 86-92 